\title{
ВИДЕОТОРАКОСКОПИЧЕСКИЙ ПЛЕВРОДЕЗ С ВВЕДЕНИЕМ АУТОКРОВИ ПРИ ОПЕРАЦИЯХ ПО ПОВОДУ БУЛЛЕЗНОЙ ЭМФИЗЕМЫ ЛЕГКИХ, ОСЛОЖНЕННОЙ СПОНТАННЫМ ПНЕВМОТОРАКСОМ
}

\author{
К. Л. Гафт
}

Институт общей и неотложной хирургии имени В. Т. Зайцева НАМН Украины, г. Харьков

\section{VIDEOTHORACOSCOPIC PLEURODESIS WITH AUTOBLOOD INFUSION IN PATIENTS DURING SURGERY OF BULLOUS PULMONARY EMPHYSEMA COMPLICATED BY SPONTANEOUS PNEUMOTHORAX}

\author{
K. L. Gaft \\ Zaitsev Institute of General and Emergency Surgery, Kharkov
}

Реферат

Причиной большой частоты рецидивов спонтанного пневмоторакса при распространенных формах буллезной эмфиземы легких (БЭЛ) является неэффективность существующих видов видеоторакоскопического (ВТС) плевродеза. Разработан метод плевродеза с введением аутокрови, что позволяет достичь более эффективной облитерации плевральной полости и клинического эффекта.

Ключевые слова: буллезная эмфизема легких; спонтанный пневмоторакс; видеоторакоскопия; плевродез; аутокровь.

Abstract

The reason of big relapse rate of pneumothorax in patients with disseminated bullous emphysema is the lack of efficiency of existing methods of laparoscopic pleurodesis. We elaborated a new method of pleurodesis with autoblood infusion, which allows more effective obliteration of the pleural space and the better clinical effect.

Keywords: bullous pulmonary emphysema; spontaneous pneumothorax; videothoracoscopy; pleurodesis; autoblood.

В последние годы лечебно-диагностическая тактика при БЭЛ, осложненной спонтанным пневмотораксом, совершенствуется, что связано с активным развитием видеотехники и внедрением ВТС вариантов стандартных хирургических вмешательств [1]. При этом резекционные методы операций на легких дополняют различными видами плевродеза. В настоящее время разработаны и внедрены ВТС аналоги практически всех видов плевродеза [2 - 4]. Париетальную плевру обрабатывают с использованием монополярной и аргоно-плазменной коагуляции, внутриплеврально инсталлируют тальк, спирт и другие химические реагенты.

Однако как при открытых, так и ВTC вмешательствах применяемые виды плевродеза обусловливают существенные осложнения (исследования в этой области свидетельствуют о риске возникновения канцерогенеза вследствие введения в плевральную полость талька и других реагентов) либо недостаточно эффективны при лечении генерализованной формы БЭЛ [5-8].

Альтернативой существующим ВТС способам плевродеза может быть плевродез с введением в полость плевры крови пациента. Впервые подобная методика описана в 1987 г. C. Robinson, который однократно ввел 50 мл крови в плевральную полость для лечения ригидного пневмоторакса [9].

Смысл способа в том, что возникающий при быстром введении крови в плевральную полость свернувшийся гемоторакс впоследствие трансформировался в наслоения фибрина, которые обусловливали формирование спаек и препятствовали возникновению ригидного пневмоторакса. Однако из-за большой частоты осложнений (в первую очередь, гнойно-септических) метод не получил широкого распространения [10].
Основываясь на патофизиологии процессов, происходящих в плевральной полости после введения в нее крови, мы разработали собственный метод плевродеза, который использовали после ВТС резекции легкого у больных при распространенных формах БЭЛ.

Цель исследования: анализ эффективности разработанного метода плевродеза с введением аутокрови по сравнению с таковой коагуляционного лестничного плевродеза у пациентов при распространенных формах БЭЛ, осложнившейся спонтанным пневмотораксом.

\section{МАТЕРИАЛЫ И МЕТОДЫ ИССЛЕДОВАНИЯ}

Нами проанализированы результаты лечения 58 больных, оперированных в клинике в период с 2007 по 2015 г. по поводу распространенной формы БЭЛ, осложнившейся спонтанным пневмотораксом. Всем больным после первичной ВТС и вери- 
фикации распространенности буллезного процесса в целях радикальной хирургической коррекции произведена атипичная ВТС резекция. У 28 пациентов (контрольная группа) после ВТС резекции осуществляли стандартный ВТС коагуляционный лестничный плевродез по задней полуокружности плевральной полости с I по VIII ребро. У 30 больных (основная группа) после аналогичной резекции осуществляли плевродез с введением аутокрови по разработанной методике. Эффективность плевродеза оценивали в послеоперационном периоде по данным УЗИ, определяли совокупную толщину висцеральной и париетальной плевры в различных участках грудной полости.

Исследование проводили троекратно: после удаления плеврального дренажа (как правило, 4 - 6-е сутки), на 14-е сутки и через 2 мес после операции.

\section{РЕЗУЛЬТАТЫ}

У всех пациентов контрольной группы по данным первого УЗИ отмечено выраженное утолщение плевры в зоне плевродеза по задней поверхности грудной стенки - до 5,5 - 7 мм, умеренное утолщение плевры в реберно- диафрагмальных синусах - до 3,5 мм, связанное, по нашему мнению, с реакцией плевры на выпот, и незначительное (2 - 2,2 мм) утолщение плевры в области купола плевры. На 14-е сутки в области купола и синусах толщина плевры составляла в среднем 1,7 мм, в зоне плевродеза - 3,3 - 3,5 мм. Через 2 мес у 15 больных на всех исследованных участках толщина плевры составляла 0,7 - 0,9 мм; у 13 больных отмечено незначительное (до 2 мм) утолщение плевры в зоне плевроде$3 a$.

У 8 пациентов контрольной группы в сроки до 2 лет обнаружен рецидив спонтанного пневмоторакса. По данным ВТС у 6 из них, помимо возникновения новых булл, расположенных под линией швов и в краевых сегментах легкого, в зоне лестничного плевродеза выявлены немногочисленные плохо васкуляризированные шнуроподобные сращения висцеральной и па- риетальной плевры. Этим больным на 2 - 3-е сутки выполнена ВТС атипичная ререзекция и апикальная плеврэктомия. Течение послеоперационного периода у них без осложнений. У 2 пациентов буллезный процесс приобрел признаки генерализованного; в зоне плевродеза наблюдали единичные плоскостные сращения, легко разъединяемые при контакте.

После ВТС им произведены химический плевродез и редренирование плевральной полости, что позволило достичь стойкого пневмостаза только на 10 - 12-е сутки; у 1 из них рецидив повторился дважды в течение 1 года.

В основной группе у всех больных за 1 сут до операции заготавливали 500 мл крови. После ВТС резекции этой кровью равномерно орошали легкое и внутреннюю поверхность грудной стенки в направлении от купола к переднему реберно-диафрагмальному синусу. Кровь затем эвакуировали через плевральный дренаж в стерильный флакон и повторяли орошение. Процедуру производили 2 - 3 раза, небольшие сгустки крови, зафиксировавшиеся на париетальной и висцеральной плевре, не удаляли, плевральную полость не санировали.

По данным УЗИ после удаления дренажа в синусах, области купола и по задней поверхности плевральной полости выявлены напластования фибрина, прочно спаянные с плеврой, толщиной 7,1 - 8,0 мм; у больных сохранялась субфебрильная температура тела до 6-х суток. На 14-е сутки толщина плевры на всех исследованных участках составляла 3,7 - 4,5 мм; через 2 мес у 25 больных до 2,2 - 2,7 мм, у 5 - на фоне аналогичных процессов в зоне купола плевры отмечали так называемые «окна» истончения плевры до 2 мм.

В течение 2 лет только у одного больного основной группы возник рецидив в виде малого парциального спонтанного пневмоторакса. По данным ВТС у него отмечен массивный спаечный процесс практически во всех отделах плевральной полости, за исключением небольшой зоны в области купола плевры, приле- жащей к линии шва. На этом участке легкого обнаружены новые тонкостенные буллы, одна из которых была перфорирована, что явилось причиной пневмоторакса. Остальная поверхность легкого из-за густой, обильно васкуляризированной сети сращений и выраженного утолщения висцеральной плевры практически недоступна осмотру. Пациенту произведена коагуляция булл, редренирование плевральной полости; течение послеоперационного периода без осложнений.

\section{ОБСУЖДЕНИЕ}

Результаты проведенного исследования позволяют сделать общий вывод о том, что введение аутокрови оказывает более выраженное влияние на листки плевры, чем их механическое повреждение. Оно достигается как путем практически тотальной обработки поверхности легкого и грудной стенки, так и патофизиологических реакций, запускаемых аутокровью. Неоднократное орошение листков плевры большим объемом аутокрови обусловливает истощение фибринолитических свойств плевры, образовавшиеся многочисленные сгустки не успевают дефибринироваться и, вследствие выпадения фибрина, возникает обширный спаечный процесс.

Это подтверждают данные первого УЗИ, проведенного после операции у больных основной группы, когда толщина фибринноплеврального «конгломерата» достигала 8 мм. Затем, вследствие репаративных процессов, характерных для поздних стадий воспаления, толщина «коры» увеличивается в среднем до 4 мм, через 2 мес составляет 2,5 мм. Вместе тем, данные ВТС при рецидивах свидетельствуют о значительно более выраженном межплевральном ангиогенезе у больных основной группы, очевидно, вследствие сохранения листков плевры. Фактически между листками плевры управляемо моделируются процессы, характерные для преобразования свернувшегося гемоторакса, что способствует облитерации плевральной полости и достижению клинического эффекта. 


\section{Выводы}

1. Причиной большой частоты рецидивов спонтанного пневмоторакса при распространенных формах БЭЛ является неэффективность существующих видов ВТС плевродеза.
2. Внедрение предложенного метода позволяет более эффективно и в то же время физиологично воздействовать на плевру, а применение аутокрови исключает аллергические, токсические и канцерогенные реакции организма.

\section{ЛИTEPATYPA/REFERENCES}

1. Lang-Lazdunski L, Coonar AS. A prospective study of autologous «blood patch» pleurodesis for persistent air leak after pulmonary resection. Eur J Cardiothorac Surg. 2004;26:897-900.

2. Cagirici U, Sahin B, Cakan A, et al. Autologous blood patch pleurodesis in spontaneous pneumothorax with persistent air leak. Scand Cardiovasc J. 1998;32:75-8.

3. Dumire R, Crabbe MM, Mappin FG, et al. Autologous "blood patch" pleurodesis for persistent pulmonary air leak. Chest. 1992;101:64-6.

4. Mallen JK, Landis JN, Frankel KM. Autologous «blood patch» pleurodesis for persistent pulmonary air leak. Chest. 1993;103:326-7.

5. Droghetti A, Schiavini A, Muriana P, et al. Autologous blood patch in persistent air leaks after pulmonary resection. J Thorac Cardiovasc Surg. 2006;132:556-9.

6. Ando M, Yamamoto M, Kitagawa C, et al. Autologous blood-patch pleurodesis for secondary spontaneous pneumothorax with persistent air leak. Respir Med. 1999;93:432-4.

3. Метод прост в выполнении, не требует специальной подготовки персонала и материальных затрат, может быть рекомендован для использования в практике общехирургических стационаров.

7. Blanco $\mathrm{BI}$, Sala BJ, Canto $\mathrm{AH}$, et al. Pleurodesis with autologous blood: the results of a series of 17 cases with more than a year of follow-up. Rev Clin Esp. 1997;197:406-10.

8. Martinez-Escobar S, Ruiz-Bailen M, Lorente-Acosta MJ, et al. Pleurodesis using autologous blood: a new concept in the management of persistent air leak in acute respiratory distress syndrome. J Crit Care. 2006;21:209-16.

9. Robinson CL. Autologous blood for pleurodesis in recurrent and chronic spontaneous pneumothorax. Can J Surg. 1987;30:428-9.

10. Rivas de Andres JJ, Blanco S de la TM. Postsurgical pleurodesis with autologous blood in patients with persistent air leak. Ann Thorac Surg. 2000;70:270-2. 